\title{
Successful use of Hemospray to control refractory post-polypectomy bleeding
}

A 66-year-old man was referred to our department for screening colonoscopy. A polyp was found in the sigmoid colon (size $25 \mathrm{~mm}$, Paris classification 0-Ip, narrow-band imaging international colorectal endoscopic [NICE] classification 2). After the submucosal injection of diluted epinephrine and lifting ( $\bullet$ Fig.1), endoscopic mucosal resection was done.

Immediately after the procedure, spurting post-polypectomy bleeding occurred. Because attempts to control the bleeding with clips were unsuccessful ( $\bullet$ Fig. 2), a decision was made to apply Hemospray (Cook Medical, Bloomington, Indiana, USA). More than $20 \mathrm{~g}$ of hemostatic powder was applied through the 10-Fr catheter, and the bleeding was arrested (๑ Fig. 3, Video 1).

At the 24-hour second-look colonoscopy, coagulated blood was noted to be retained in the colonic lumen, but no fresh blood was seen at the polypectomy site. At the 7-day follow-up colonoscopy, a postpolypectomy ulcer with a large-caliber blood vessel was seen ( $\bullet$ Fig.4), which was subsequently closed with the combined use of clips and a nylon snare in a "tulip bundle" fashion. No perforation, symptomatic systemic embolism, or bowel obstruction was observed during the 30-day follow-up period.

Post-polypectomy bleeding is a wellknown complication of colonic polypectomy, with a reported incidence ranging from $0.6 \%$ to $8.6 \%$ [1]. The risk is higher in patients who have a sessile polyp larger than $1 \mathrm{~cm}$ or a pedunculated polyp, such as the one in our patient [2]. Acute postpolypectomy bleeding is often immediately apparent and amenable to endoscopic therapy, and the use of hemoclips is a preferred treatment modality [3].

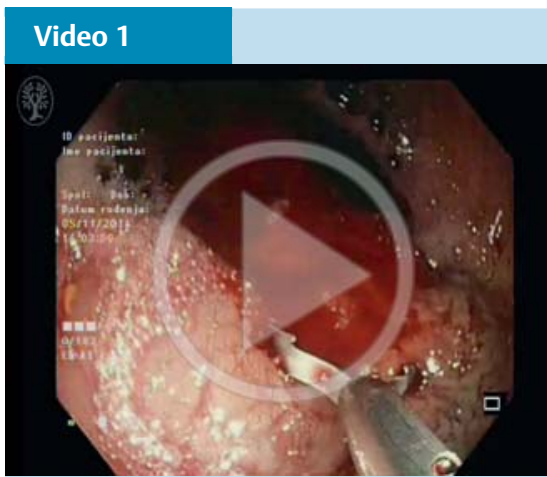

Application of Hemospray in a patient with post-polypectomy bleeding.

However, in our patient, a failure of hemostasis was observed, possibly caused by the retraction of a blood vessel deeper into the colonic wall and the subsequent inability to grasp the vessel with a clip.

The use of Hemospray for the control of colonic hemorrhage was demonstrated recently [4]. However, the efficacy of this hemostatic agent in controlling spurting post-polypectomy bleeding was limited [4]. Our case contrasts with this finding, possibly because a larger amount of the powder was applied to the site of bleeding.

Although the use of Hemospray in the lower gastrointestinal tract is off label, we believe that our case adds to the experience with this novel treatment modality, in which Hemospray is applied for "rescue" hemostasis in the context of spurting post-polypectomy bleeding after failure of the primary hemostatic modality.

\section{Endoscopy_UCTN_Code_TTT_1AQ_2AZ}

Competing interests: None

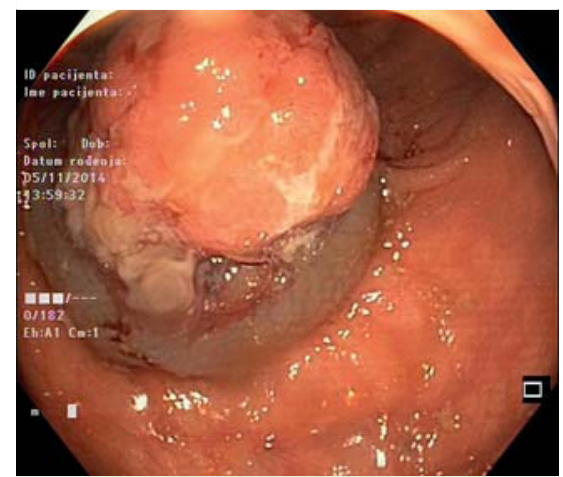

Fig. 1 A polyp with a thick stalk located in the sigmoid colon, detected in a 66-year-old man undergoing screening colonoscopy. Diluted epinephrine was injected.

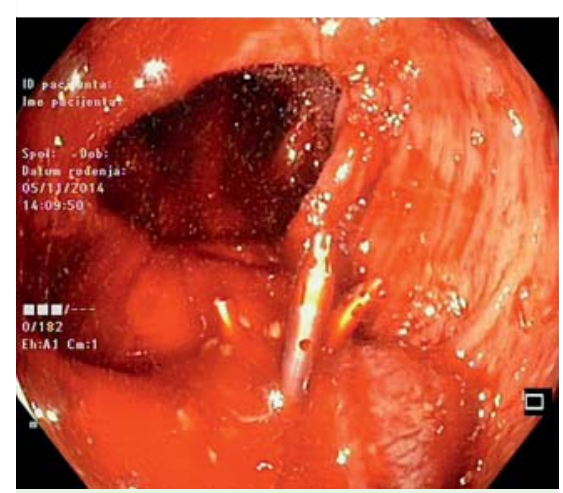

Fig. 2 Refractory post-polypectomy bleeding. Attempts to arrest the bleeding with clips failed.

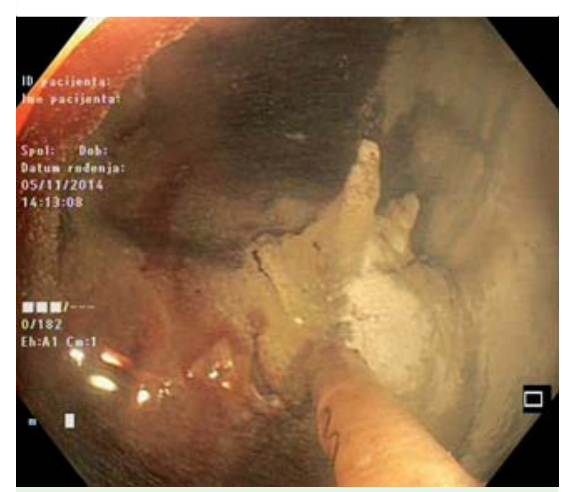

Fig.3 Application of Hemospray.

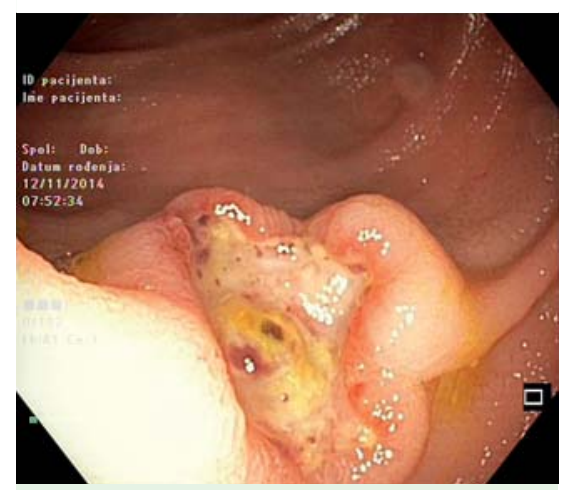

Fig. 4 Follow-up colonoscopy at 7 days revealed a post-polypectomy ulcer. 
Hrvoje Ivekovic ${ }^{1}$, Branko Bilic ${ }^{1}$, Pave Markos ${ }^{1}$, Nadan Rustemovic ${ }^{1}$, Rajko Ostojic ${ }^{1}$, Klaus Mönkemüller ${ }^{2}$

${ }^{1}$ University Hospital Centre Zagreb, Department of Gastroenterology and Hepatology, Zagreb, Croatia

2 Division of Gastroenterology \& Hepatology, UAB School of Medicine, Birmingham, Alabama, USA

\section{References}

1 Kapetanos D, Beltsis A, Chatzimavroudis G et al. Postpolypectomy bleeding: incidence, risk factors, prevention, and management. Surg Laparosc Endosc Percutan Tech 2012; 22: $102-107$

$2 \mathrm{Kim}$ HS, Kim TI, Kim WH et al. Risk factors for immediate postpolypectomy bleeding of the colon: a multicenter study. Am J Gastroenterol 2006; 101: 1333-1341

3 Conway JD, Adler DG. ASGE Technology Committee. et al. Endoscopic hemostatic devices. Gastrointest Endosc 2009; 69: 987-996

4 Holster IL, Brullet E, Kuipers EJ et al. Hemospray treatment is effective for lower gastrointestinal bleeding. Endoscopy 2014; 46: $75-78$
Bibliography

DoI http://dx.doi.org/

10.1055/s-0034-1392865

Endoscopy 2015; 47: E466-E467

(C) Georg Thieme Verlag KG

Stuttgart · New York

ISSN 0013-726X

\section{Corresponding author}

\section{Hrvoje Ivekovic, MD, PhD}

University Hospital Centre Zagreb

Department of Gastroenterology and Hepatology Kispaticeva 12

10000 Zagreb

Croatia

Fax: +385-1-2388200

hrvoje.ivekovic@gmail.com 